\title{
A HOMOGENEOUS EARTHQUAKE CATALOG OF INTERMEDIATE-DEEP FOCUS GLOBAL SEISMICITY: COMPLETENESS AND SPATIO-TEMPORAL ANALYSIS
}

\section{Tsampas A.D. ${ }^{1}$, Scordilis E.M. ${ }^{1}$, Papazachos C.B. ${ }^{1}$ and Karakaisis G.F. ${ }^{1}$}

${ }^{1}$ Aristotle University of Thessaloniki, Faculty of Geology, Department of Geophysics, GR-54124, Thessaloniki,Greece,atsampas@geo.auth.gr,manolis@geo.auth.gr,kpapaza@geo.auth.gr, karakais@geo.auth.gr

\begin{abstract}
A homogeneous with respect to magnitude earthquake catalog is compiled, particularly focusing on the global intermediate depth-deep focus seismicity and by exploiting data of almost half-century. Within a two-step compilation process, we take advantage of 10 robust conversion equations produced exclusively for intermediate depth and deep focal data (Tsampas et al., 2016). Initially, magnitudes of different scales and several origins are converted into proxy moment magnitudes $\left(M_{w} *_{\sim} M_{w}\right)$ and a weighted mean-value aggregation procedure is then applied for all events with estimated $M_{w} *$. Therefore, a homogeneous magnitude scale (equivalent to $M_{w}$ ) is obtained as result of individual correlations between different magnitude scales and the moment magnitude $\left(M_{w}\right)$ scale, yielding a unique magnitude value per event. Moreover, through implementing a simple optimization scheme, a composed, unique depth value per event is estimated, utilizing focal data from multiple resources. In the end and after validating magnitude's $(M)$ reliability, a brief spatio-temporal analysis of the provided catalog is performed, revealing its potential for further exploitation in large scale seismological surveys or other research studies of global interest.

Keywords: Homogeneous catalog, proxy moment magnitude, intermediate-depth and deep-focus earthquakes, spatio-temporal analysis.

\section{Пврі́ $\eta \psi \eta$}

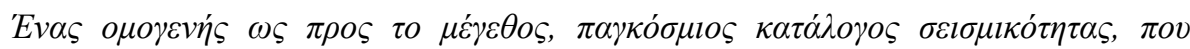

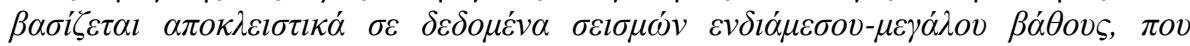

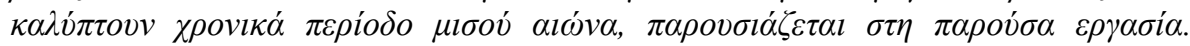

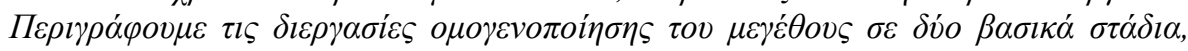

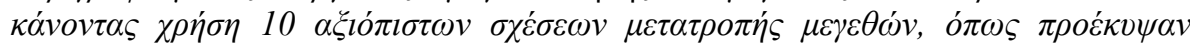

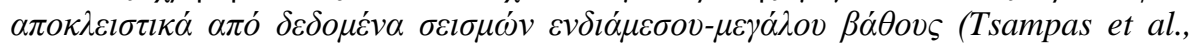

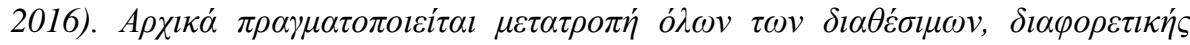

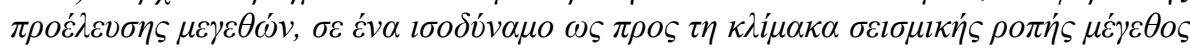

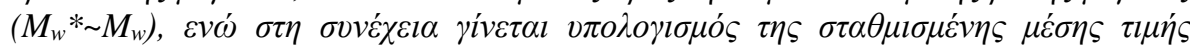

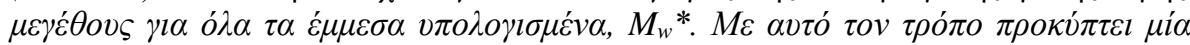

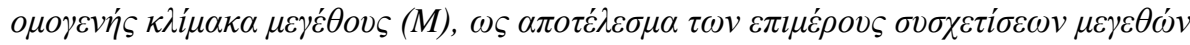

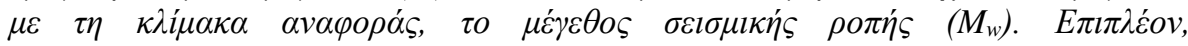

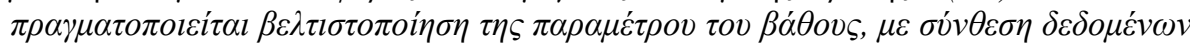

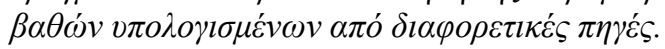




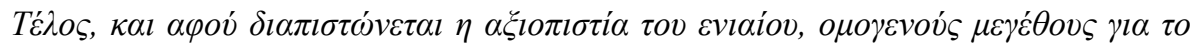

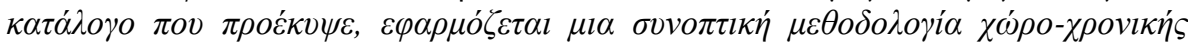

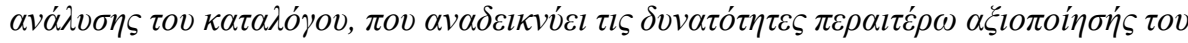

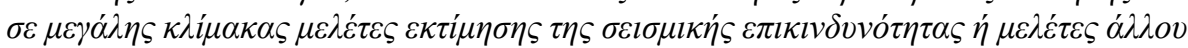

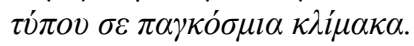

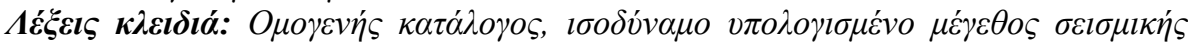

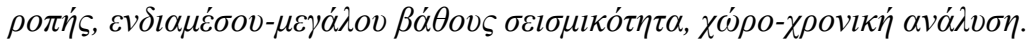

\section{Introduction}

Earthquake catalogs are nowadays considered as an essential tool for seismic hazard assessment implementations and for all kind of global or regional seismicity studies. A critical prerequisite that should be fulfilled by any modern earthquake catalog regardless its spatial (e.g. global, regional, local) and/or its temporal (e.g. historical or instrumental reference periods) extent, is its homogenization level, with respect to its magnitude and its epicentre accuracy parameters.

In terms of earthquake size, the use of multiple magnitude scales still remains a significant part of the earthquake measurement process, although seismic moment $\left(\mathrm{M}_{0}\right)$ is widely acknowledged as the most appropriate physical measure for representing this quantity. Thus, the ideal case of a single, prevailing magnitude, reported by individual seismological centres and networks, still remains debatable. This reveals an almost "de facto" necessity for magnitude homogenization during earthquake catalog compilation processes, through which the numerous magnitude estimates of different origin could produce a unified, mean magnitude $\mathrm{M}$, equivalent to the, proposed by Hanks and Kanamori (1979), moment magnitude scale $\left(\mathrm{M}_{\mathrm{w}}\right)$.

For this reason, through examining the behavior of different magnitude scales exclusively for intermediate-depth and deep-focus earthquakes, a series of robust, calibrated with the moment magnitude scale converting relationships, was formerly defined, by applying a General Orthogonal Regression (GOR) analysis (Tsampas et al., 2016). These results are implemented here to create an accurate and homogeneous with respect to magnitude global catalog of intermediate-depth and deepfocus earthquakes, extending over a wide time-period of almost half century.

\section{Data}

In order to build a homogeneous (with respect to magnitude) earthquake catalog, we acquired all available hypocenters determined by instrumental recordings of globally occurred intermediatedepth and deep focus earthquakes ( $\mathrm{h} \geq 60 \mathrm{~km}$ ), during the period 1965-2012. Relying primarily on ISC's (International Seismological Centre) database, our initial global dataset included more than 350,000 events, taking into account all available information published in ISC bulletins. This global dataset was later refined by employing only those scales for which proven and robust GOR correlations with moment magnitude $\left(\mathrm{M}_{\mathrm{w}}\right)$ scale have been defined (Tsampas et al., 2016).

Thus, certain scales, as the body wave $\left(\mathrm{m}_{\mathrm{b}}, \mathrm{m}_{\mathrm{B}}\right)$ and the surface wave $\left(\mathrm{M}_{\mathrm{s}}\right)$ magnitude reported by ISC, NEIC (National Earthquake Information Center), IDC (CTBTO's International Data Centre), MOS (Institute of Physics of the Earth), BJI (CENC's World Data Center for Seismology) were included in our data. In addition, Japan's regional scale (MJMA, Japan Meteorological Agency) which has been specified as equivalent to the $20 \mathrm{~s}-\mathrm{M}_{\mathrm{s}}$ scale (Noguchi, 1979), has also been used in the catalog, using a lower cut-off at $\mathrm{M}_{\mathrm{JMA}}=2.5$, due to numerous regional events reported by JMA.

Following similar studies of global shallow seismicity (Utsu, 2002; Scordilis, 2006), the resulting conversion equations which correlate the above described scales with the reference scale of $\mathrm{M}_{\mathrm{w}}$, are given by Table 1 . Moreover, the interval of $\mathrm{M}_{\mathrm{x}}\left(\mathrm{M}_{\mathrm{x} \min }, \mathrm{M}_{\mathrm{xmax}}\right)$ values over which a quadratic or linear GOR fit was robustly estimated is also indicated (see Table 1), denoting the range over which the respective conversion relationships could be validly considered (Fuller, 1987; Castellaro et al., 2006). 
Table 1 - Proposed end-user relationships (Tsampas et. al., 2016) for the conversion of calibrated $M_{x}$ scales to the proxy $M_{w} *$ scale (almost equivalent to moment magnitude, $M_{w}$ ) after applying GOR analysis.

\begin{tabular}{|c|c|c|c|c|c|c|c|}
\hline & \multirow{2}{*}{$\begin{array}{c}\text { Calibrated } \\
\text { Scales } \\
\left(\mathbf{M}_{\mathbf{x}}\right)\end{array}$} & \multicolumn{3}{|c|}{$\begin{array}{c}\text { GOR equations converting } \\
\qquad M_{x} \text { to } M_{w} * \\
\end{array}$} & \multirow[t]{2}{*}{$\begin{array}{c}\text { Res.SD } \\
(\sigma)\end{array}$} & \multirow[t]{2}{*}{$\mathbf{M}_{\mathbf{x} \min }$} & \multirow[t]{2}{*}{$\mathbf{M}_{\mathbf{x m a x}}$} \\
\hline & & $\mathbf{b}_{2}$ & $\mathbf{b}_{1}$ & $\mathbf{a}_{0}$ & & & \\
\hline \multirow{5}{*}{ 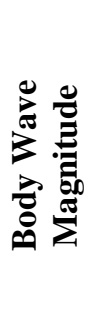 } & $\mathrm{m}_{\mathrm{b}} \mathrm{IN}$ & 0.165 & -0.372 & 2.816 & 0.214 & 3.6 & 6.3 \\
\hline & $\mathrm{m}_{\mathrm{b}} \mathrm{MOS}$ & 0.143 & -0.288 & 2.716 & 0.257 & 4.3 & 6.5 \\
\hline & $\mathrm{m}_{\mathrm{b}} \mathrm{BJI}$ & -0.204 & 3.515 & -7.418 & 0.239 & 4.5 & 6.4 \\
\hline & $\mathrm{m}_{\mathrm{B}} \mathrm{BJI}$ & -0.207 & 3.617 & -7.984 & 0.215 & 4.6 & 7.9 \\
\hline & $\mathrm{m}_{\mathrm{b}} \mathrm{IDC}$ & 0.045 & 0.837 & 0.382 & 0.226 & 3.3 & 6.1 \\
\hline \multirow{4}{*}{ 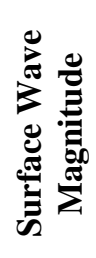 } & $\mathrm{M}_{\mathrm{S}} \mathrm{IN}$ & - & 0.790 & 1.551 & 0.199 & 3.1 & 7.9 \\
\hline & $\mathrm{M}_{\mathrm{s}} \mathrm{IDC}$ & -0.140 & 2.105 & -1.120 & 0.229 & 2.9 & 6.5 \\
\hline & $\mathrm{M}_{\mathrm{s}} \mathrm{BJI}$ & 0.004 & 0.792 & 1.300 & 0.224 & 4.2 & 7.3 \\
\hline & $\mathrm{M}_{\mathrm{s}} \mathrm{MOS}$ & -0.006 & 0.850 & 1.540 & 0.219 & 4.4 & 7.7 \\
\hline 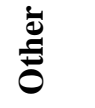 & $\mathrm{M}_{\mathrm{JMA}}$ & - & 0.923 & 0.370 & 0.233 & 3.5 & 7.4 \\
\hline
\end{tabular}

As a last step in our dataset compilation process, moment magnitudes published from GCMT, NEIC and Japan's NIED were also integrated in our set and were jointly evaluated thereinafter. Moreover, magnitude data originating from well-known catalogs of global seismicity (Rothe, 1969; Båth and Duda, 1979; Karnik, 1996; Engdahl and Villaseñor, 2002) were also considered and used, mostly for cross-checking purposes and improvement of the ISC-NEIC's reported $\mathrm{m}_{\mathrm{b}}$ and $\mathrm{M}_{\mathrm{s}}$ information.

This contribution of supplementary data has enriched the NEIC's $\mathrm{M}_{\mathrm{s}}$ and $\mathrm{M}_{\mathrm{w}}$ magnitude data, especially in cases of large events occurred back in 1960s and 1970s. Following latter entry and after discarding erroneous entries (doublets or false events), a new upgraded version of our intermediate depth and deep focal set was developed.

In addition to the collected magnitude data, focal depth information is also of particular importance for our intermediate depth and deep focus seismicity study. Therefore, focal depths estimated from more than one sources were acquired, including ISC's primary and $\mathrm{pP}$ depths estimations, depths from the EHB catalog (Engdahl et al., 1998) and as also depths originating from the GCMT (Ekström et al., 2012) and the PDE (USGS-NEIC, nowadays under ANSS) seismic moment databases.

All above depth information was incorporated to our dataset, with the EHB and pP depths being considered as focal parameters of higher accuracy and also recognized as almost equivalent (Frohlich, 2006). As a result, a unique depth value per event was preferred according to a simple priority scheme favouring pP-depths, EHB-depths and ISC primary solution depths, followed by the GCMT and PDE depths. 


\section{Magnitude Homogenization Procedure and Validation}

In order to estimate a homogeneous magnitude (M) scale for the whole magnitude range of the catalog, a simple, two step algorithm was implemented through appropriate code (Scordilis, personal communication), considering both statistical impacts and errors in $\mathrm{M}$ scale calculations.

As first step, the linear or quadratic equations described in Table 1 were applied and conversions for every calibrated magnitude scale to a proxy moment magnitude $\mathrm{M}_{\mathrm{w}} *$ were obtained. Then, a unique magnitude value, $\mathrm{M}$, per event was estimated, as the weighted mean of all the available $\mathrm{M}_{\mathrm{w}}$. An appropriate statistical weighting factor for each participating magnitude was considered, using the inverse of the standard deviation $(\sigma)$ of the respective converting relation:

\section{Equation 1}

$$
M_{(i)}=\frac{\sum_{i=1}^{n}\left[\left(1 / \sigma_{i}\right) \cdot M_{w_{i}}^{*}\right]}{\sum_{i=1}^{n}\left(1 / \sigma_{i}\right)}
$$

where $\mathrm{M}_{(\mathrm{i})}$ is the estimated equivalent moment magnitude, $\mathrm{n}$ is the number of participating magnitude values, $\mathrm{M}_{\mathrm{wi}}{ }^{*}$ and $\sigma_{\mathrm{i}}$ is the corresponding standard deviation (SD) determined from GOR analysis, of each converting relation (see Table 1). The respective standard deviation of the $\mathrm{M}_{(\mathrm{i})}$ estimation is given by the relation:

\section{Equation 2}

$$
\sigma_{M_{(i)}}=\frac{n}{\sqrt{n-1} \sum_{i=1}^{n}\left(1 / \sigma_{i}\right)}
$$

The $\mathrm{M}_{(\mathrm{i})}$ estimations were repeated after omitting individual values exceeding the $\pm 2 \sigma$ confidence limits (95\% confidence interval).

In order to graphically validate and briefly illustrate the quality of the estimated homogeneous $\mathrm{M}$ magnitudes a composite comparison approach was evaluated (Figure 1). More specifically, the variation of the mean weighted magnitude $\mathrm{M}_{\mathrm{f}(\mathrm{i})}$ against the $\mathrm{M}_{\mathrm{w}} *$ approximations (resulting from the direct implementation of Table's 1 equations) was examined by considering:

\section{Equation 3}

$$
M_{f(i)}=\frac{\sum_{i=1}^{n-1}\left[\left(1 / \sigma_{i}\right) \cdot M_{w_{i}}^{*}\right]}{\sum_{i=1}^{n-1}\left(1 / \sigma_{i}\right)}
$$

denoting that in $\mathrm{M}_{\mathrm{f}(\mathrm{i})}$ 's case, only ( $\mathrm{n}-1$ ) available $\mathrm{M}_{\mathrm{w}(\mathrm{i})}$ * magnitude values per solution are taken into account, excluding the one that is under validation.

These $\mathrm{M}_{\mathrm{f}(\mathrm{i})}$ values are depicted in Figure 1, plotted against the corresponding $\mathrm{M}_{\mathrm{w}(\mathrm{i})}$ * values. It must be noted that both $\mathrm{M}_{(\mathrm{i})}$ and $\mathrm{M}_{\mathrm{f}(\mathrm{i})}$, are considered as equivalent in case of $\mathrm{M}_{\mathrm{w}} \mathrm{H}, \mathrm{M}_{\mathrm{w}} \mathrm{N}$ or $\mathrm{M}_{\mathrm{w}} \mathrm{NIED}$ validated scales, as in general $\mathrm{M}_{\mathrm{w}}$ was considered as the reference, independent variable, in our GOR procedure. 


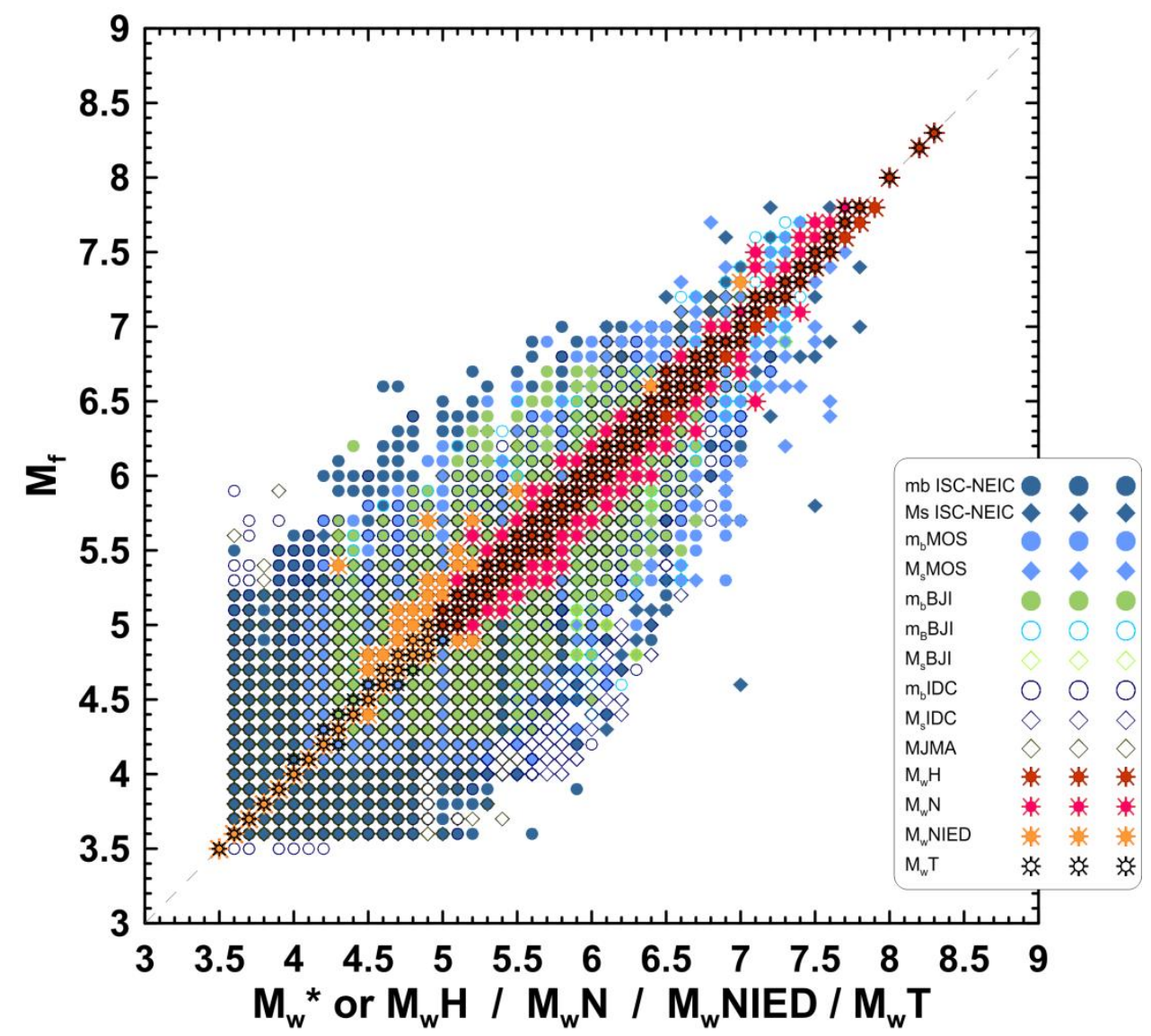

Figure 1 - Summary graph illustrating $M_{f}$ 's variation of each calibrated magnitude, against the corresponding $M_{w i} *$ (see text for more detailed description). Dashed line depicts the bisector.

In Figure's 1 composite plot, every discrete mean magnitude $\mathrm{M}_{\mathrm{f}(\mathrm{i})}$ was assigned with separate symbol, allowing us to draw conclusions regarding the precision of the estimated magnitude $\mathbf{M}_{(\mathrm{i})}$. Thus, it becomes obvious that a fairly good agreement exists between the $\mathbf{M}_{\mathrm{f}}$ and $\mathbf{M}_{\mathrm{w}} *\left(\right.$ or $\mathrm{M}_{\mathrm{w}}$ ) values, as indicated also by the symmetric scatter clouding across bisector line. This symmetric distribution appears to prevail for the vast majority of different magnitude scales examined here, denoting in a direct way the prevalent robustness of the GOR conversion equations presented in Table 1 and as also their further statistical impact to the applied homogeneous magnitude, M, determination process.

\section{Comprehensive Spatio-temporal Catalog Analysis}

\subsection{Epicenters Spatial Distribution}

As result of the homogenization procedure applied to collected magnitude data and by considering a composed, unique depth value from multiple focal resources, an earthquake catalog with single per event values regarding the focal parameters and magnitudes, is created. Two maps showing the spatial distribution of the catalog's earthquakes are presented, displaying the global intermediate depth and deep focus seismicity that covers the instrumental period between 1965 and 2012 (Figures 2a and 2b). 

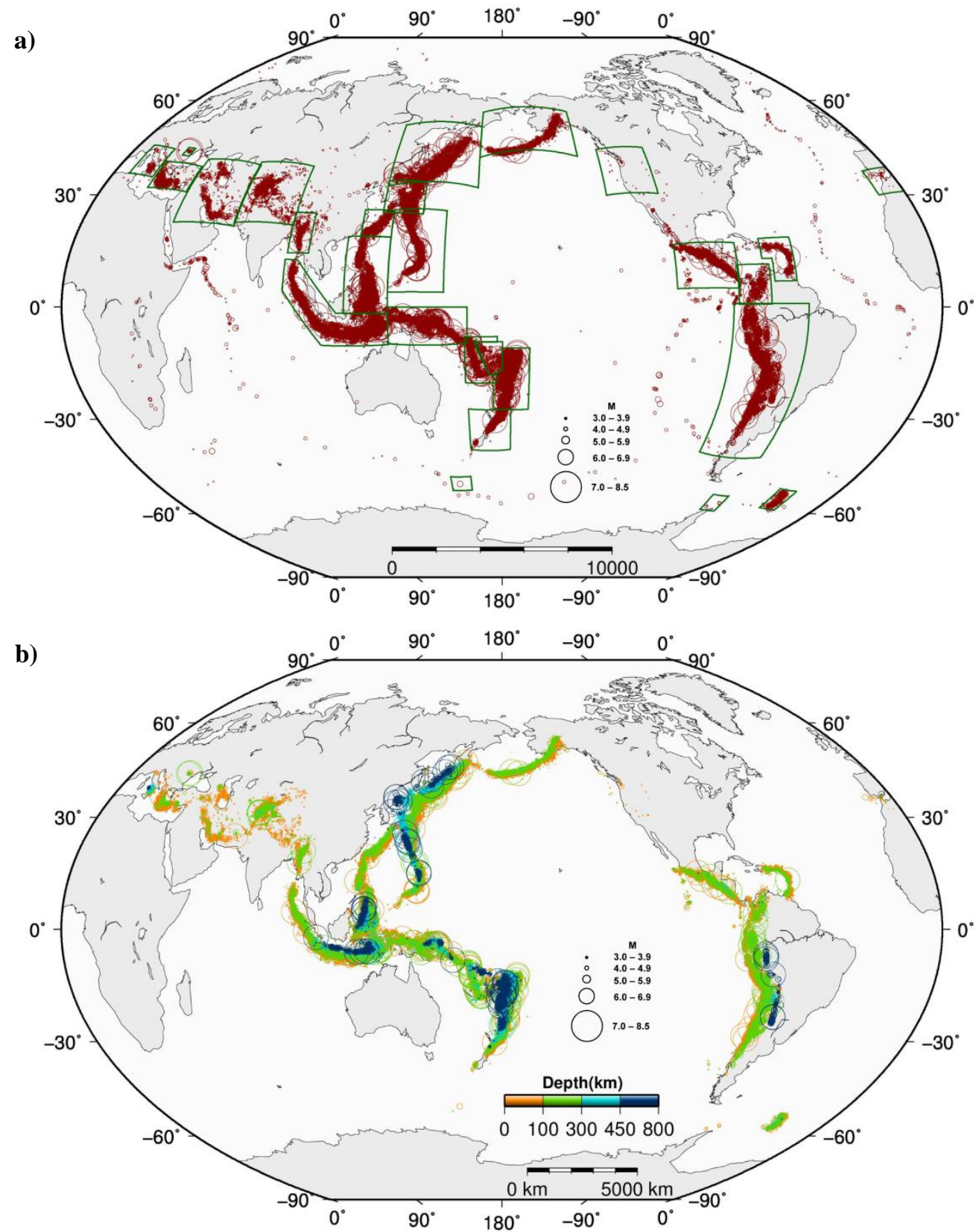

Figure 2 - Epicenter distribution of intermediate depth and deep focus global seismicity of the period 1965-2012. a) Distribution of epicentres before the spatial filtering. Green polygons delimit 27 discrete regions restricting the global intermediate depth and deep focus activity according to Frohlich (2006). b) Spatial distribution of deep seismicity after removing mid-oceanic ridge and intraplate events.

At first, a number of outlying events, occurring on the oceanic ridge transform systems or in intraplatecontinental regions was included in our dataset, mostly due to errors in hypocenter locations (Figure 2a). Such events were removed in accordance to Frohlich's (2006) conclusions, with 27 worldwide discrete geographic regions been roughly introduced, containing almost the entire global intermediate depth and deep focus seismicity (Figure 2a). Therefore, our initial compiled catalog was spatially 
reduced according to these regions. The improved version of catalog's epicenter distribution, indicating also the magnitude and depth spread, is then presented in Figure $2 \mathrm{~b}$.

\subsection{Magnitude and Depth Distribution}

Figure's 3 histograms present the magnitude and the depth frequency-distributions respectively, as they are derived from our global dataset. It must be noted that the increased number of small $(3.5<\mathrm{M}<4.5)$ events is mainly originated from Japan's JMA network.
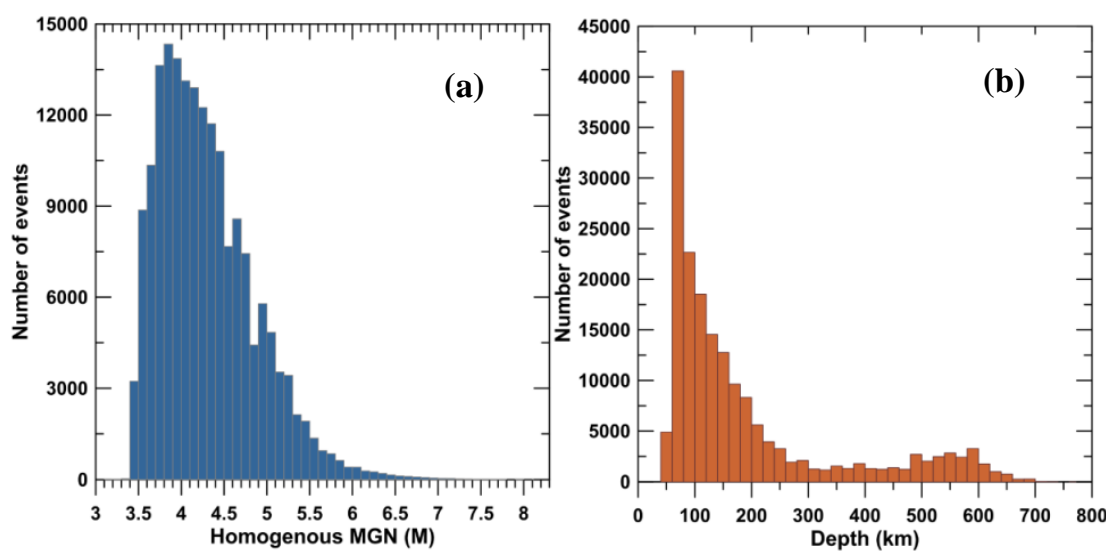

Figure 3 - Magnitude (left) and depth (right) distribution histograms for intermediate depth and deep focus earthquakes included in our catalog.

On the other hand, the depth's distribution histogram reveals a high concentration at depths of 50$120 \mathrm{~km}$ with a local peak around $60-70 \mathrm{~km}$ (Figure $3 \mathrm{~b}$ ). Subsequently, a gradual decrease of activity can be identified approaching the intermediate depth-deep seismicity transition zone, close to 350 $\mathrm{km}$. Moving deeper, the seismicity rate is slightly increased as deep focal events occur near the discontinuity of $410 \mathrm{~km}$, followed by a more normal increased rate for the transition's zone section between 500 and $700 \mathrm{~km}$.

\subsection{Completeness Magnitude $\left(M_{c}\right)$ and b-value Distribution as Function of Time}

Unlikely to the most common procedures applied for the completeness $\left(\mathrm{M}_{\mathrm{c}}\right)$ magnitude estimation, e.g. Gutenberg-Richter's (1944) power law or the frequency-magnitude distribution (FMD) spatial analysis, a detection of $\mathrm{M}_{\mathrm{c}}$ variation with time is attempted in the present study. By following similar past implementations (e.g. Woessner and Wiemer, 2005), a bootstrap analysis, part of ZMAP software toolbox (Wiemer, 2001), was tested. Therefore, within a 90-95\% interval of confidence, the maximum curvature procedure of 200 bootstraps was selected, using a sample window of 100 events with an overlap of 10 events. As a result, after checking the variations of $M_{c}$ magnitude with time for several regions, four distinct complete time periods can be roughly defined: i) 1965-1979, ii) 1980-1994, iii) $1995-2008$ and iv) 2009-2012. Given the fourth's period short duration, we preferred to further examine only the first three intervals mentioned above.

Also, the considerable drop of $\mathrm{M}_{\mathrm{c}}$ 's values after 1995 should be noted here. This is attributed to IDC's GSETT-3 project during which an effort was made to conduct operationally realistic tests of rapid collection, distribution and processing of seismic data, through utilizing a worldwide monitoring network (Ringdal, 1994). This change, which turned out to be an artifact, was identified during the generation of a homogeneous catalog of surficial epicenters compiled for mid-Atlantic's transform ridge area and based on ISC's bulletin data (Teza et al., 2016, personal communication).

In order to analyze the evaluation of Mc and b-value within space and time, we similarly employed ZMAP's maximum curvature procedure, as this was described above. Accordingly, by considering 
circles of $400 \mathrm{~km}$ radius with their centers moving within a step of $1 \mathrm{x} 1 \mathrm{deg}$ for longitude and latitude respectively, 100 bootstraps with a minimum of 20 events per circle were applied.

According to Figure $4, M_{c}$ 's spatial distribution shows a characteristic gradual reduction during the three examined periods and as we're moving towards present. A remarkable reduction of $\mathrm{M}_{\mathrm{c}}$ 's range is especially observed during the later decades (1980-1994 and 1995-2008) due to the expansion of the modern seismological networks. However, the 1995 result is also expected as a result of ISC's procedure, previously discussed.

On the other hand and for the interval of 1965-1979, higher $\mathrm{M}_{\mathrm{c}}$ values can be detected in two main regions: i) the south-eastern Asia and, ii) the Scotia's arc islands, both indicating poor network coverage in those regions at the examined period.

Besides, the corresponding b-value spatial distribution values as those were calculated for the three examined time intervals are depicted in Figure 5. According to this, $\mathrm{b}$ obtains high values near trenches and further away from the back-arc basins, especially for rather shallow subduction zones, characterized by intermediate depth activity, e.g. Hellenic Arc and Ryukyu-Taiwan (Okinawa Trough) region in Figure 5c. This could be also explained by the b-value's default definition, as in such regions strong events $(M>6.0)$ are rare and moderate intermediate depth events are dominating.

\section{Conclusions}

For the current work, global intermediate depth and deep focus data were collected and processed in order to produce a homogenous (with respect to magnitude) and reliable (concerning focal depths) earthquake catalog. For the magnitude homogenization procedure, the moment magnitude, $\mathrm{M}_{\mathrm{w}}$, was considered as reference magnitude scale. A series of 10 robust conversion relations was utilized, facilitating the implementation of the homogenization process that was applied here (Tsampas et al., 2016). Furthermore, the estimated magnitude $\mathrm{M}$, equivalent to the moment magnitude scale, was validated through appropriate testing methodology. An attempt for composing multiple depth information of different origin and optimize the depth into a unique representative value was also performed.

The completeness magnitude $\mathrm{M}_{\mathrm{c}}$ variation with time and space was examined, resulting to the identification of three different periods of completeness during which noticeable changes in seismicity can be observed. During these periods, the b-value spatial variation was evaluated, providing additional information regarding the seismicity features during the three time intervals that were examined.

The final created catalog covers the instrumental period 1965-2012, including 179,167 events from all the subduction zones worldwide and from the 27 discrete geographic regions defined by Frohlich (2006). Thus, an essentially well-qualified dataset was produced, which can be considered as a useful tool, appropriate for large scale implementations such as seismic hazard studies of regional or global scale.

\section{Acknowledgements}

We would like to thank an anonymous reviewer for the constructive review of the present paper. This research has been co-financed by the European Union (European Social Fund - ESF) and Greek national funds through the Operational Program "Education and Lifelong Learning" of the National Strategic Reference Framework (NSRF) - Research Funding Program: THALES. Investing in knowledge society through the European Social Fund. Project SEISMO FEAR HELLARC. Geophysics Department Contribution Number 806/2013. The Generic Mapping Tools software, version 4.5.6 (Wessel et al., 2013) was used for producing the maps of the present study. 

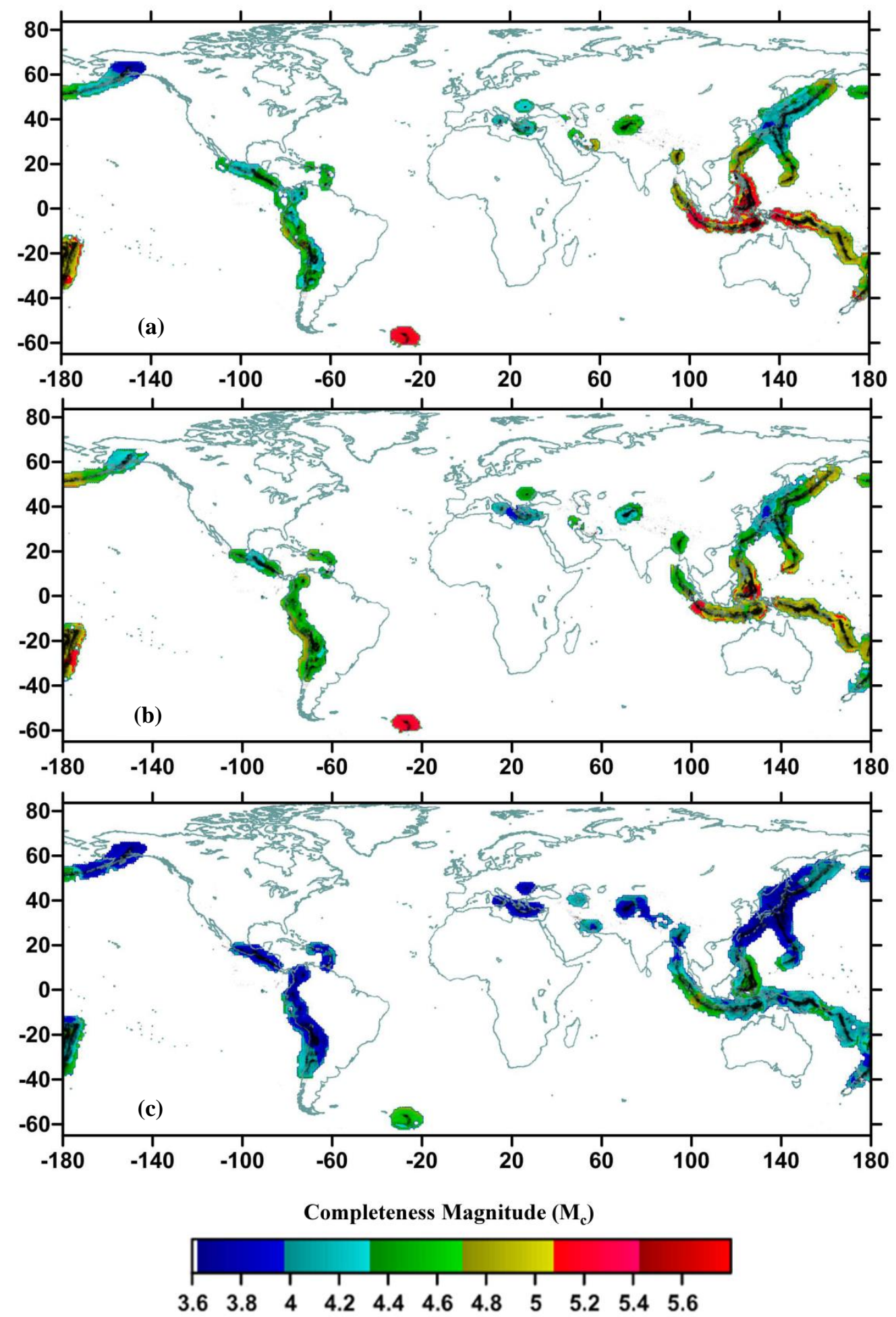

Figure 4 - Spatial variation of completeness magnitude $\left(M_{c}\right)$ for the three discrete periods of completeness examined: a) 1965-1979, b) 1980-1994 and c) 1995-2008. 

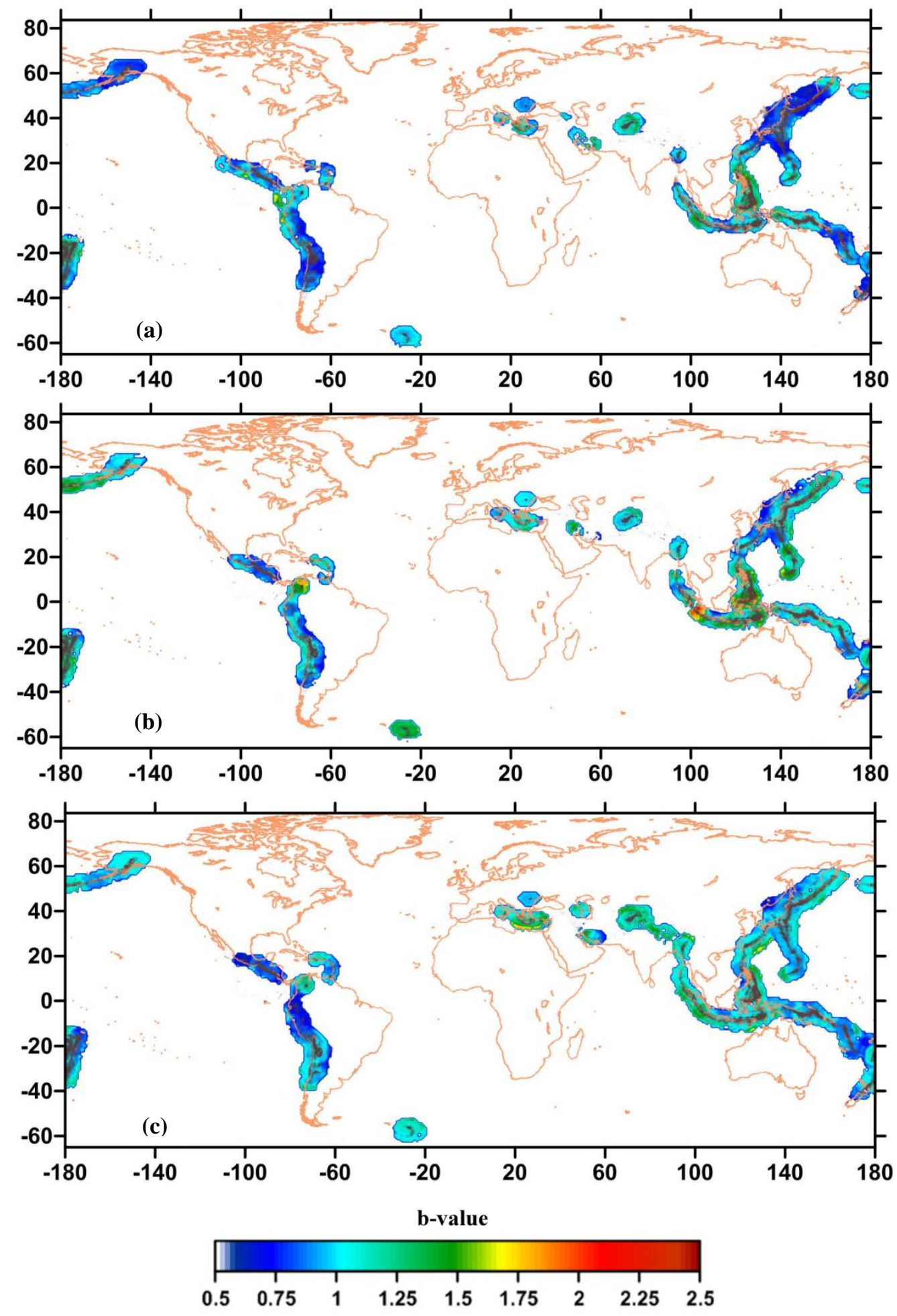

Figure 5 - Spatial variation of b-value for the three distinct complete time periods examined: a) 1965-1979, b) 1980-1994 and c) 1995-2008. 


\section{References}

Abe, K. and Kanamori, H., 1979. Temporal variation of the activity of intermediate and deep focus earthquakes, J. Geophys. Res., 84(87), 3589-3595.

Båth, M. and Duda, S.J., 1979. Some aspects of global seismicity: Report No. 1-79, Seismological Institute, Uppsala, Sweden, 41 pp.

Castellaro, S., Mulargia, F. and Kagan. Y.Y., 2006. Regression problems for magnitudes, Geophys. J. Int., 165, 913-930.

Ekström, G., Nettles, M. and Dziewonski, A.M., 2012. The global CMT project 2004-2010: centroid-moment tensors for 13,017 earthquakes, Phys. Earth Planet. Inter., 200-201, 1-9.

Engdahl, E.R., Van der Hilst, R. and Buland, R., 1998. Global teleseismic earthquake relocation with improved travel times and procedures for depth determination, Bull. Seism. Soc. Am., 88, 722-743.

Engdahl, E.R. and Villaseñor, A., 2002. Global Seismicity: 1900-1999. In: Lee, W.H.K., Kanamori, H., Jennings, P.C. and Kisslinger, C., eds., International Handbook of Earthquake and Engineering Seismology, Part A, Chapter 41, Academic Press, 665-690.

Frohlich, C., 2006. Deep Earthquakes, Cambridge University Press, Cambridge, England.

Fuller, W.A., 1987. Measurement Error Models, Wiley, New York.

GCMT, 2012. Global Centroid Moment Tensor (GCMT) project at Lamont-Doherty Earth Observatory (LDEO) of Columbia University/. http://www.globalcmt.org/CMTsearch.html.

Gutenberg, B. and Richter, C.F., 1944. Frequency of earthquakes in California, Bull. Seism. Soc. Am., 34, 185-188.

Hanks, T. and Kanamori, H., 1979. A moment magnitude scale, J. Geophys. Res., 84, 2348-2350.

International Seismological Centre (ISC), 2012. On-line Bulletin, Internat. Seis. Cent., Thatcham, United Kingdom. Available online at: http://www.isc.ac.uk/iscbulletin/search/bulletin.

Karnik, V., 1996. Seismicity of Europe and the Mediterranean. In: Klima, K., ed., Academy of Sciences of the Czech Republic, Geophysical Institute, 28 pp. plus earthquake catalogue.

MATLAB ${ }^{\circledR}$ and Statistics Toolbox Release, 2009b. The MathWorks, Inc., Natick, Massachusetts, United States.

National Earthquake Information Center, (NEIC), 2011. Earthquake Hazards Program. Available online at: http://neic.usgs.gov/neis/epic/index.html.

Noguchi, S., 1979. On the relation between surface-wave magnitude and JMA magnitude J, Faculty of Science, Hokkaido Univ. Ser., VII, 6, 213-224.

Ringdal, F., 1994. GSETT-3: a test of an experimental international seismic monitoring system, Annali di Geofisica, 37, 241-245.

Rothe, J.P., 1969. The seismicity of the earth, 1953-1965. Paris, United Nations Educational, Scientific and Cultural Organization, $336 \mathrm{pp}$.

Scordilis, E.M., 2006. Empirical global relations converting Ms and mb to moment magnitude, Journal of Seismology, 10, 225-236.

SOPAR, 2012. Source Parameter Search (SOPAR) - Moment Tensor and Broadband Source Parameter Search, USGS-NEIC. http://earthquake.usgs.gov/earthquakes/eqarchives/sopar.

Teza, E., Scordilis, E.M., Papazachos, C.B. and Karakaisis, G.F., 2016. An Earthquake Catalog of Mid-Atlantic Ridge, Bull. Geol. Soc. Greece, Proc. of the 14th International Congress, Thessaloniki (in submission).

Tsampas, A.D., Scordilis, E.M., Papazachos, C.B. and Karakaisis, G.F., 2016. Global Magnitude Scaling Relations for Intermediate-Depth and Deep-Focus Earthquakes, Bull. Seism. Soc. Am., 106(2), 418-434.

Wessel, P., Smith, W.H.F., Scharroo, R., Luis, J.F. and Wobbe, F., 2013. Generic Mapping Tools: Improved version released, Eos Trans. Am. Geophys. Union, 94, 409-410.

Wiemer, S., 2001. A software package to analyze seismicity: ZMAP, Seismological Research Letters, 72, 2, 374-383.

Woessner, J. and Wiemer, S., 2005. Assessing the quality of earthquake catalogues: Estimating the magnitude of completeness and its uncertainties, Bull. Seism. Soc. Am., 95(2), 684-698.

Utsu, T., 2002. Relationships between magnitude scales. In: Lee, W.H.K., Kanamori, H., Jennings, P.C. and Kisslinger, C., eds., International Handbook of Earthquake and Engineering Seismology, Part A, Chapter 81, 733-746. 